\title{
Protein and essential amino acid intake in males who do and do not consume protein supplements
}

\author{
L. Doyle and R. Warner \\ Department of Health, Sport and Exercise Science, School of Health Sciences, Waterford Institute of Technology, \\ Republic of Ireland
}

Worldwide, supplement use amongst athletes ranges between 40 and $60 \%^{(1)}$. Despite the fact supplement use is commonplace no study has measured the effect of taking supplements on protein and amino acid intake. Additionally the recommended daily intake for protein varies depending on athlete type ${ }^{(2)}$. Requirement for protein has also been suggested to vary according to lean body mass ${ }^{(3)}$. The aim of this study was to examine protein intake of exercising males who do and do not take protein supplements and investigate whether they were achieving their desired intake level according to current recommendations.

Following ethical approval 65 physically active males who did not take protein supplements and 62 males who took supplements were recruited. Subjects completed a 3 day food diary, were asked if they eat a high protein diet and recorded any supplements consumed. Dietary analysis was completed through CompEat ${ }^{\mathrm{TM}}$. Lean body mass was measured by a DEXA scan. Supplemental protein and essential amino acid intake were obtained from the supplement label.

Table 1. Protein and essential amino acid intakes of males who do and do not take protein supplements.

\begin{tabular}{|c|c|c|c|c|c|c|c|c|}
\hline & \multicolumn{2}{|c|}{$\begin{array}{l}\text { Normal diet } \\
(n 46) 81 \mathrm{~kg}\end{array}$} & \multicolumn{2}{|c|}{$\begin{array}{l}\text { Extra dietary } \\
\text { protein } \\
\left(\begin{array}{ll}n & 19) \\
8 & 83 \mathrm{~kg} \\
\end{array}\right.\end{array}$} & \multicolumn{2}{|c|}{$\begin{array}{l}\text { Extra protein } \\
\text { supplements } \\
(n \text { 14) } 79 \mathrm{~kg} \\
\end{array}$} & \multicolumn{2}{|c|}{$\begin{array}{l}\text { Extra dietary protein } \\
\text { and supplements } \\
(n 48) 87 \mathrm{~kg}\end{array}$} \\
\hline & RDA & Mean & RDA & Mean & RDA & Mean & RDA & Mean \\
\hline Protein $(\mathrm{g})$ & 100.56 & 25.98 & 112.12 & 38.56 & 161.25 & 51.09 & 202.75 & 73.43 \\
\hline$\% \mathrm{RDA}^{\mathrm{a}}$ & 104.48 & 27.21 & 107.39 & 35.63 & 136.77 & 57.81 & 155.96 & 65.51 \\
\hline$\% \operatorname{RDA}^{\mathrm{b}}(\mathrm{g} / \mathrm{Kg} \mathrm{LBM})$ & 57.72 & 12.67 & 63.81 & 20.35 & 93.18 & 26.45 & 103.99 & 34.73 \\
\hline Isoleucine $^{\mathrm{c}}(\mathrm{g})$ & 1.54 & 1.85 & 1.58 & 1.90 & 1.50 & 6.20 & 1.65 & 5.75 \\
\hline Leucine $^{1}(\mathrm{~g})$ & 3.40 & 3.26 & 3.49 & 3.25 & 3.32 & 8.04 & 3.65 & 9.37 \\
\hline Valine $^{\mathrm{c}}(\mathrm{g})$ & 1.94 & 2.28 & 1.99 & 2.33 & 1.90 & 5.48 & 2.09 & 5.97 \\
\hline Phenylalanine $^{\mathrm{c}}(\mathrm{g})$ & 2.67 & 1.93 & 2.74 & 1.97 & 2.61 & 3.70 & 2.87 & 3.55 \\
\hline Tryptophan $^{\mathrm{c}}(\mathrm{g})$ & 0.41 & 0.52 & 0.42 & 0.52 & 0.40 & 1.25 & 0.44 & 1.40 \\
\hline $\operatorname{Histidine}^{\mathrm{c}}(\mathrm{g})$ & 1.13 & 1.11 & 1.16 & 1.15 & 1.10 & 2.10 & 1.22 & 2.36 \\
\hline Methionine $^{\mathrm{c}}(\mathrm{g})$ & 1.54 & 0.92 & 1.58 & 0.94 & 1.50 & 1.89 & 1.65 & 2.42 \\
\hline Lysine $^{\mathrm{c}}(\mathrm{g})$ & 3.08 & 2.43 & 3.15 & 2.58 & 3.00 & 6.45 & 3.31 & 7.41 \\
\hline Threonine $^{c}(\mathrm{~g})$ & 1.62 & 1.60 & 1.66 & 1.66 & 1.58 & 4.47 & 1.74 & 5.51 \\
\hline
\end{tabular}

${ }^{\mathrm{a}}$ Protein RDA based on individual physical activity levels ${ }^{(2)}$.

${ }^{\mathrm{b}}$ Protein intake based on lean body mass is recommended at $2.75 \mathrm{~g} / \mathrm{Kg} \mathrm{LBM}$.

${ }^{c}$ RDA's for essential amino acids based on Dietary Reference Intakes (DRIs) for Macronutrients and Energy.

Protein intake calculated based on physical activity levels ${ }^{(2)}$ ) was $37 \%$ and $56 \%$ greater than recommended intakes with supplement use. When intake was calculated based on lean body mass, subjects not consuming supplements, taking extra dietary protein only or extra protein supplements only, failed to meet their protein requirements. Subjects relying on diet only for essential amino acids failed to meet their recommended intake for phenylalanine, methionine and lysine with these shortfalls being eliminated through supplement intake.

This work was supported by Strand I funding under the Technological Sector Research grant.

1. Petroczi A \& Naughton DP (2007) J Occup Med Toxicol 2, 4.

2. Campbell B, Kreider RB, Ziegenfuss T et al. (2007) J Int Soc Sport Nut 26, 8.

3. Sears B. The Zone Diet; 1999. 